\title{
Experimental Models of Dermatophytosis
}

\author{
Emilie Faway, Marc Thiry, Bernard Mignon, and Yves Poumay
}

\begin{abstract}
Dermatophytosis is a superficial fungal infection of the keratinized structures of the host. Since the last decade, this mycosis became an important health concern due to an increasing prevalence and to the limited number and efficacy of available treatments. Several experimental models have then been developed in order to improve knowledge about this infection and to design new therapeutic strategies. This chapter presents the variety of dermatophytosis experimental models and their contribution in the understanding of mechanisms used by dermatophytes to adhere and to invade the host tissue. Their support to study the establishment of effective antifungal defenses by the host is also summarized. The usefulness of these models for testing the efficacy of antifungal compounds is finally discussed.
\end{abstract}

\section{Keywords}

Dermatophytosis $\cdot$ Trichophyton rubrum $\cdot$ Microsporum canis $\cdot$ Experimental models · Skin equivalents · Reconstructed human epidermis · Adhesion · Invasion $\cdot$ Host responses $\cdot$ Antifungal efficacy

E. Faway $\cdot$ Y. Poumay $(\triangle)$

URPHYM-NARILIS, Faculty of Medicine, University of Namur, Namur, Belgium

e-mail: yves.poumay@unamur.be

M. Thiry

Cell and Tissue Biology Unit, GIGA-Neurosciences, University of Liège, Liège, Belgium

B. Mignon

FARAH, Faculty of Veterinary Medicine, University of Liège, Liège, Belgium 


\section{Abbreviations}

$\begin{array}{ll}\text { AMP } & \text { Antimicrobial peptides } \\ \text { CFU } & \text { Colony-forming unit } \\ \text { GM-CSF } & \text { Granulocyte-macrophage colony-stimulating factor } \\ \text { IFN } \gamma & \text { Interferon-gamma } \\ \text { IL } & \text { Interleukin } \\ \text { Lap } & \text { Leucine aminopeptidase } \\ \text { Mep } & \text { Metalloprotease } \\ \text { NET } & \text { Neutrophil extracellular trap } \\ \text { PAS } & \text { Periodic acid-Schiff } \\ \text { PMN } & \text { Polymorphonuclear neutrophils } \\ \text { RFE } & \text { Reconstructed feline epidermis } \\ \text { RHE } & \text { Reconstructed human epidermis } \\ \text { Sub } & \text { Subtilisin protease } \\ \text { TGF } & \text { Transforming growth factor } \\ \text { TLR } & \text { Toll-like receptors } \\ \text { TNF } \alpha & \text { Tumor necrosis factor alpha }\end{array}$

\section{$1 \quad$ Introduction}

Dermatophytosis is the most common fungal disease in the world with a current prevalence estimated between $20 \%$ and $25 \%$ of the general population [1-4], but reaching more than $50 \%$ among some populations at risk such as diabetic patients or sport practitioners $[5,6]$. This infection is caused by specific filamentous and keratinolytic fungi named dermatophytes. Several species are identified and classified into three groups according to their natural host or environment [7]:

- Geophilic species, for example Nannizzia gypsea and Nannizzia fulva (previously known as Microsporum gypseum and Microsporum fulvum, respectively), generally feed on keratinized wastes found in the environment and frequently remain nonpathogenic.

- Zoophilic species preferentially infect specific animal hosts but can also infect other animal species including humans. For example, the preferred hosts for Microsporum canis and Trichophyton benhamiae (previously known as Arthroderma benhamiae) are, respectively, cats and rodents.

- Anthropophilic species, as for example Trichophyton rubrum and Trichophyton interdigitale, exclusively infect humans.

Among all dermatophyte species able to cause infections in humans, T. rubrum is responsible for a vast majority of dermatophytosis in humans: indeed, depending on the geographical areas, between $50 \%$ and $90 \%$ of cases are due to T. rubrum $[2,8]$. 
In immunocompetent patients, dermatophytosis affects the keratinized structures of the host, namely hairs, nails, and epidermis, resulting in superficial lesions with erythema, dryness, and desquamation as clinical symptoms $[9,10]$. The severity of lesions partly depends on the species involved, zoophilic and geophilic dermatophytes usually inducing more severe inflammatory responses in human hosts in comparison with anthropophilic species that are well adapted to humans as a consequence of more efficient mechanisms for immunoevasion [11-13]. Anyway, lesions resulting from dermatophytosis cause pain and discomfort and their anesthetic appearance is clearly responsible for individual shame and low selfesteem in concerned patients, along with reduced social interactions and quality of life [14-16].

Despite their overwhelming prevalence, dermatophytosis has been yet poorly studied. Thus, many questions regarding the mechanisms deployed by dermatophytes to invade host tissues remain to be addressed. Similarly, other questions concerning the establishment of an adequate immune response in infected host require further investigation. Moreover, while antifungal agents currently available are effective against dermatophytes, these drugs have several limitations such as extended duration of the treatment, associated toxicity, especially encountered when oral administration is needed, and finally emergence of resistant strains [17].

During the last decades, several in vivo, in vitro, and ex vivo experimental models of dermatophytosis have been developed in order to answer outstanding questions. This chapter aims to describe various models useful for studying dermatophytosis, with a special focus on skin equivalent models, to depict their current contribution in the understanding of the multiple steps involved in host infection by dermatophytes, as well as to present their potential use in performing efficacy testing of antifungal compounds.

\section{Experimental Models of Dermatophytosis}

The increase in dermatophytosis prevalence observed since the last decade has gradually raised the interest of the scientific community for the study of this infection. This has led to the development and diversification of experimental models of dermatophytosis over the last few years.

\subsection{Aleurioconidia or Arthroconidia as Infective Elements Initiating Dermatophytosis}

Spores are quiescent fungal unicellular particles characterized by high mechanical resistance and low metabolic activity. They represent the initial stage of fungal development, able to reactivate, germinate, and produce new mycelium when environmental conditions are favorable [18]. Spores are physiologically produced by fungi to ensure survival in adverse conditions, as well as dispersion in the 
environment of individuals which can adhere to host tissue before starting a new infectious process. Dermatophytes are able to produce two kinds of spores: aleurioconidia arising terminally or laterally from the hyphae (microconidia corresponding to one-celled aleurioconidia and macroconidia to several successive cells detaching together at the end of hyphae), and arthroconidia resulting from fragmentation of hyphae. Transmission and scanning electron microscopy analysis performed on aleurioconidia and arthroconidia adhering over corneocytes in suspension revealed that the cell wall of arthroconidia is thicker than that of aleurioconidia, and that germination of arthroconidia occurs faster after adhesion [19]. Moreover, arthroconidia appear more resistant to certain antifungal drugs (e.g., fluconazole, griseofulvin, itraconazole) than microconidia [20]. In addition to these intrinsic differences, aleurioconidia, although they are extensively produced by dermatophytes cultured in vitro, have never been observed in vivo on lesions [21]. Conversely, arthroconidia are efficiently produced in vivo by dermatophytes.

In order to create adequate models for dermatophytosis, the use of arthroconidia as infective elements seems therefore more appropriate. In practice, arthroconidia can be produced in vitro following the procedure described by Tabart et al. [22]. Practically, after approximately 2 -week growth on nutrient-rich agar, the fungal mass is recovered by scrapping, and cultured for additional 2-3 weeks in conducive conditions that combine a nutrient-poor culture medium and a $12 \% \mathrm{CO}_{2}$ atmosphere. Unicellular elements, corresponding to arthroconidia, are finally isolated after agitation and filtration of the fungal material. However, aleurioconidia are used in most studies (e.g., [12, 23-26]), because of the ease and speed of their production in vitro: only 2-week culture on nutrient-rich agar before agitation and filtration steps. To date, only a few studies have been performed using arthroconidia (e.g., [19, 27-31]).

\subsection{In Vitro, Ex Vivo, and In Vivo Models of Dermatophytosis}

In the past, simple models of dermatophytosis were developed to describe the early steps of the infection, for instance, dermatophytes adhering to human corneocytes, either isolated after skin scrapping or in suspension, or invading sheets of cornified layer collected by the tape-stripping method [19, 30, 31]. More recently, models using nail or hair fragments infected by dermatophytes allowed the investigation of the mechanisms used by these fungi to degrade keratin [23] or permitted to characterize the expression of virulence factors by dermatophytes [24]. Although such models are suitable to monitor dermatophyte adhesion, growth, and, to a lesser extent, invasion, the absence of living keratinocytes impedes any study about the host tissue responses. Complementarily, in vitro models of keratinocytes [12, 26, 32, 33], polymorphonuclear neutrophils (PMN) [28], or macrophages [34] cultured in the presence of dermatophytes were designed to overcome those limitations. In vitro models allow the evaluation of expression and release of cytokines and antimicrobial peptides (AMP), together with the expression of toll-like receptors (TLR) or of co-stimulatory molecules by those cell types. However, even keratinocytes cultured 
as monolayers cannot be used to accurately model the epidermal adhesion and invasion processes followed by dermatophytes since they lack keratinized material.

Indeed, an ideal model to study dermatophytosis should allow simultaneous analysis of the infection steps (i.e., adhesion, germination, and tissue invasion) used by dermatophytes on one hand, and analysis of the host responses that trigger the recruitment and activation of the antifungal immune defenses on the other. In addition, such a relevant model might provide an appropriate tool to perform efficacy and toxicity assays of antifungal compounds. Ex vivo models of skin explants and in vivo animal models easily fulfill these requirements and appear therefore as promising solutions. To date, skin explants from several animal species (e.g., cats, Guinea pigs, mice) as well as from human beings have already been used to study adhesion and invasion by dermatophytes [35-39] or to characterize their expression of potential virulence factors [24]. Nonetheless, the use of skin explants, especially from humans, is quite restricted by limited availability, poor standardization of samples (for instance, regarding hairiness or body area), and large variability between the donors.

Animal models, mainly based on Guinea pigs or mice experimentally infected by dermatophytes, have been used to study steps of infection (e.g., [35, 40, 41]) or to analyze the establishment of host immune responses (e.g., [25, 29, 42]). Several animal models used to study dermatophytosis have been recently reviewed in details by Cambier et al. [43]. Nevertheless, an accurate model of dermatophytosis should mimic infection by a specific dermatophyte on tissue from an adapted host. Thereby, studying the infection of animal tissue by typical anthropophilic dermatophytes is particularly irrelevant. Indeed, there is no report of natural infection of nonhuman epidermal tissue by anthropophilic species and experimental trials devoted to infect animal tissue by the same species remain complicated because anthropophilic dermatophytes are poorly adapted to adhere and invade nonhuman tissues. Since the anthropophilic $T$. rubrum species is the most common dermatophyte involved in human infections $[2,8]$, the availability of an accurate model of infection for this dermatophyte species is required. Despite the technical limitations mentioned, models of T. rubrum dermatophytosis using mouse [44, 45], Guinea pig [46-48], or rat $[49,50]$ have nonetheless been designed. Interestingly, repeated applications of spores, previous abrasive treatments, or injection of corticosteroids prior to and after the infection are clearly required in order to obtain significant lesions. Anyway, even if they are of a considerable interest to gain knowledge about activation of the immune system in the host organism in response to dermatophyte infection, one must keep in mind that critical differences between nonhuman and human epidermis might influence data interpretation. Furthermore, the animal models have obvious ethical concerns. Therefore, there is a strong case for the development of alternative models. 


\subsection{Skin Equivalents to Create Dermatophytosis Models}

Human skin equivalents obtained in culture, including reconstructed epidermis alone or epidermis reconstructed on a dermal equivalent generally made of collagen lattice with fibroblasts, are currently the closest in vitro models that mimic cutaneous human tissues. In such models, human keratinocytes cultured at the air-liquid interface, in an environment containing appropriate growth factors and elevated $\mathrm{Ca}^{++}$concentration, undergo a complete program of differentiation that creates a stratified reconstructed tissue covered by a keratinized layer, quite similar to the human epidermis [51]. Infection models developed on skin equivalents allow studies of interactions between host tissue and pathogens, i.e., analysis of the infection process, identification of responses triggered in keratinocytes, and characterization of potential alterations induced in the tissue function. Notably, studies about cutaneous infections by the yeast Candida albicans [52], Staphylococcus aureus bacteria [53], or helminths [54] have already proven the usefulness of skin equivalents to investigate the mechanisms underlying infection.

Several reports already described infection of skin equivalents by dermatophytes. In 1995, a model involving infection by Trichophyton mentagrophytes arthroconidia of reconstructed human epidermis (RHE) has demonstrated for the first time the ability of dermatophytes to adhere onto reconstructed tissues and to invade their cell layers [55]. Later on, a model of infection by $M$. canis arthroconidia on reconstructed feline epidermis (RFE) was created to allow investigation of the adhesion mechanisms used by this dermatophyte on its natural preferred host [22]. More recently, two models of dermatophytosis based on commercially reconstructed skin tissue EpiDerm (MatTek) [26] or EpiSkin ${ }^{\circledR}$ [56] were reported. The first model was explored to evaluate the release of cytokines by keratinocytes during the infection process by several dermatophyte species, including the anthropophilic T. rubrum. Characterization of the signaling pathways simultaneously involved was also undertaken [26]. By mean of morphological analysis, the second model of dermatophytosis on EpiSkin ${ }^{\circledR}$ illustrated the different steps of the infection process by $T$. rubrum [56]. Although both models brought interesting insight and information about dermatophytosis and its pathogenesis, they used aleurioconidia as infective elements. Since aleurioconidia are only produced by dermatophytes cultured in vitro and have never been observed in vivo [21], those models cannot be considered fully representative of the in vivo conditions of infection.

Our team designed a model of dermatophytosis using RHE grown on polycarbonate filter and then infected by T. rubrum arthroconidia [27]. Practically, infection of RHE is initiated by topical application of T. rubrum arthroconidia suspended in phosphate-buffered saline to reach a final density of 1700 arthroconidia per $\mathrm{cm}^{2}$. After $4 \mathrm{~h}$ of exposure, washes are performed in order to eliminate non-adherent arthroconidia from the apical surface of RHE and to expose them again to the airliquid interface. Infected RHE are then cultured during four additional days. Morphological analysis of infected RHE revealed that arthroconidia were able to rapidly adhere to the surface of corneocytes and to produce hyphae that progressively invaded the cornified layer (Fig. 1a). When infected RHE were maintained in culture 

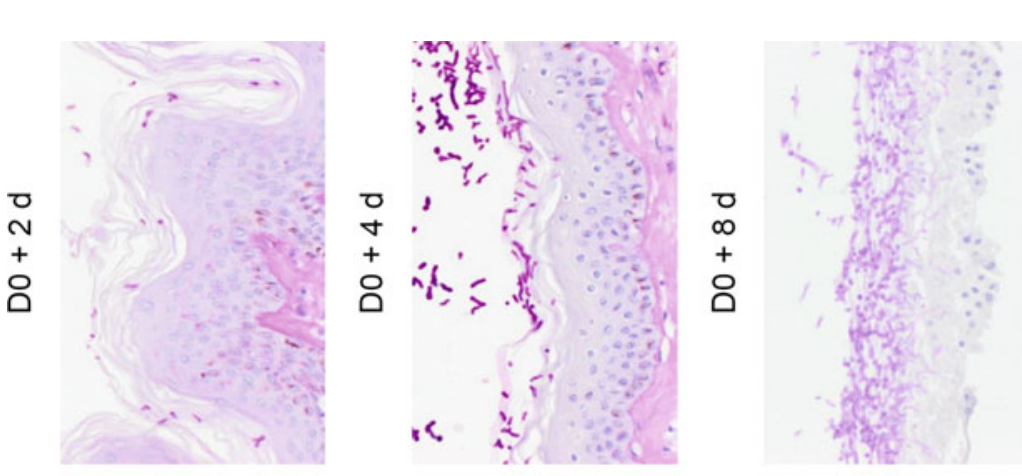

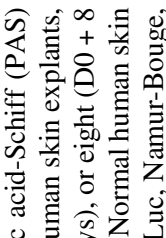

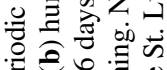

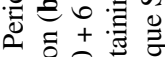

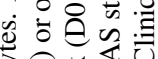

在国造

क्त की

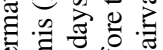
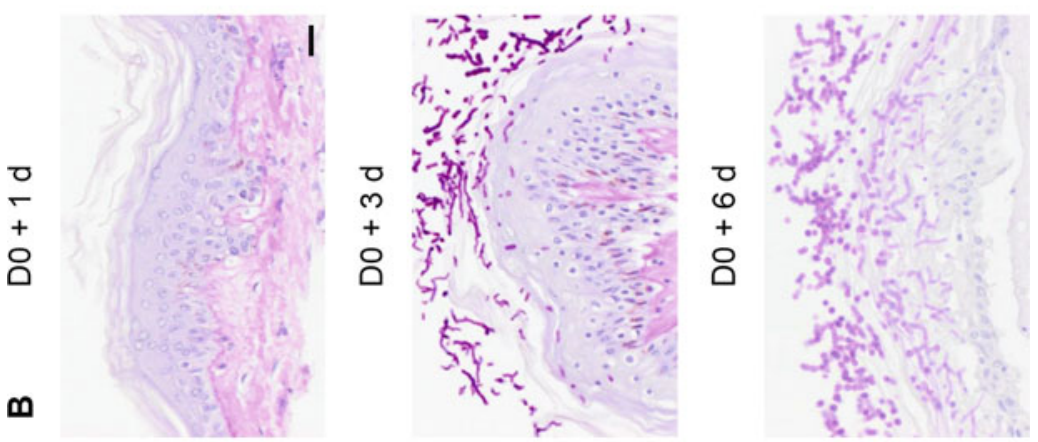

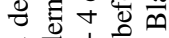

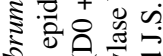

ฐ

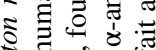
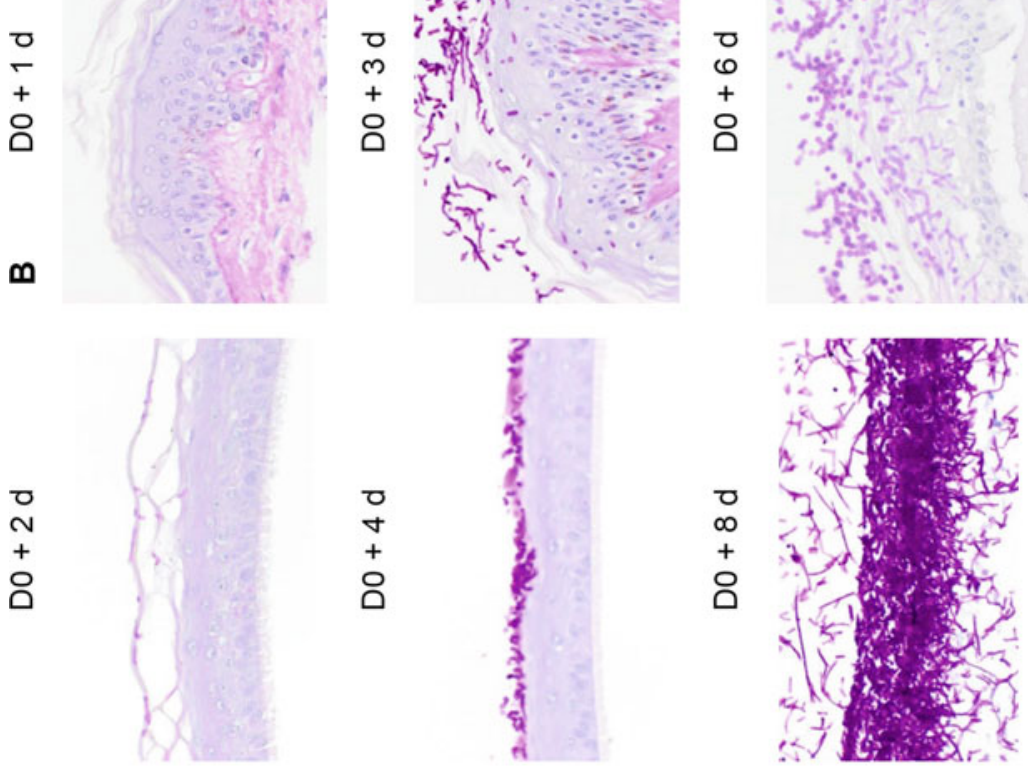

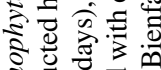

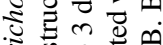

స

ล

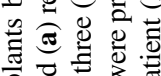

귤

芯永严

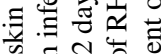

政范

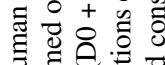

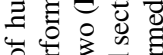

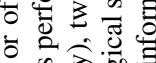

会的.

을 응웡

包

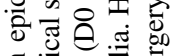

킁을

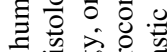

원 $\frac{0}{0}$ 를
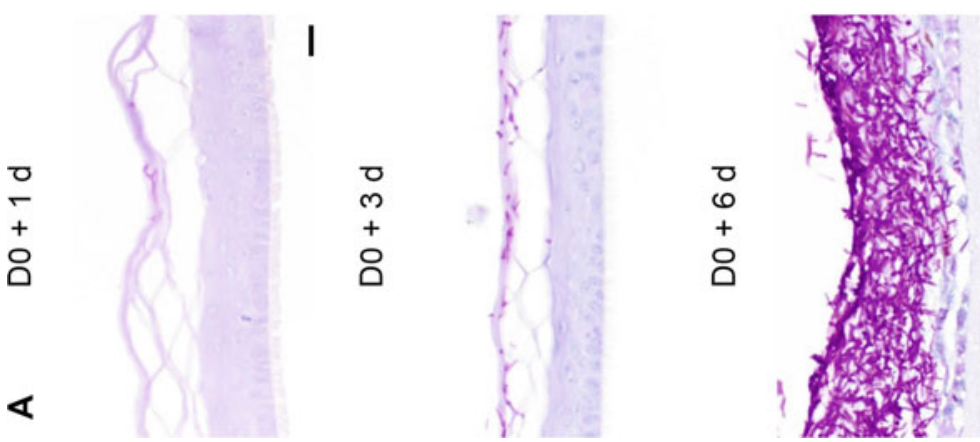

ำ

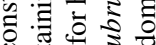

运证

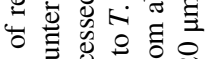

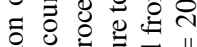

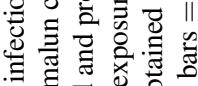

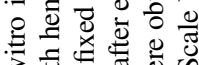

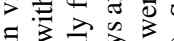

$\Xi \dot{\overline{1}}$ 交令

- .

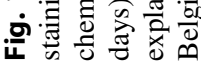


for longer periods, hyphae progressed deeper between layers of the epidermis until entire invasion of the RHE, resulting in its total disorganization. This excessive invasion is for sure not representative of in vivo lesions since the progression of fungal elements is usually restricted to the cornified layer in naturally infected normal human skin [10]. This difference can likely be explained by the absence of immune cells in RHE-based models. Therefore, culture of infected RHE is systematically interrupted at latest 4 days after exposure to arthroconidia in order to keep the model representative of in vivo lesions. In addition, using the protocol developed for RHE infection, we demonstrated that infection by T. rubrum arthroconidia happens similarly on human skin explant (Fig. 1b). This model based on infection of RHE was explored to describe the progressive steps of infection [27], as well as to identify the cellular responses of host keratinocytes and the alterations of the barrier in the infected RHE [57, 58].

The aforementioned models of dermatophytosis on skin equivalent have proven their usefulness in the evaluation of infectious processes and of human keratinocytes responses, as well as in the identification of signaling pathways triggered during these responses. In addition, such models are valuable to test efficacy of antifungal compounds $[27,55,59]$.

\subsection{Complementary Models for the Study of Experimental Dermatophytosis}

Every model described earlier allows advances in the study of dermatophytosis, but each of them is also more appropriate for the evaluation of certain aspects of the problem (Table 1). Thus, choosing a model depends essentially on the question addressed.

Adhesion is the initial step of infection during which fungal cells adhere to host substrate (i.e., keratinized structures). Ex vivo models of corneocytes in suspension and cornified layer sheets, or nail and hair fragments remain easy and adequate for the study of adhesion processes without any particular interference. Adhesion can also be studied using skin explants, skin equivalents, or animal models, but activation of host living cells (e.g., through production of AMP or recruitment of other immune components) and desquamation may influence the adhesion process. Invasion of the host tissue and consequences onto the epidermal barrier function can be evaluated in a similar manner using skin explants, skin equivalents, or animal models.

About the understanding of host tissue responses, through investigation of expression and release of cytokines, AMP, or other factors, in vitro, ex vivo, and in vivo models provide different and complementary information. In vitro models of cells cultured in suspension, as monolayers or inside RHE, allow monitoring the activation of specific cell types (e.g., keratinocytes, PMN, macrophages) independently of the others. Conversely, evaluation of the tissue reaction as a whole, including the activation of keratinocytes and of immune cells, either innate or adaptive, requires the use of in vivo animal models. For their part, ex vivo models 
Table 1 Use of different experimental models to study specific aspects of the pathogenesis of dermatophytosis

\begin{tabular}{|c|c|c|c|c|c|}
\hline & Adhesion & $\begin{array}{l}\text { Invasion and } \\
\text { effect on the } \\
\text { epidermal } \\
\text { barrier }\end{array}$ & $\begin{array}{l}\text { Activation } \\
\text { of the } \\
\text { immune } \\
\text { system }\end{array}$ & $\begin{array}{l}\text { Activation } \\
\text { of } \\
\text { individual } \\
\text { cell type }\end{array}$ & $\begin{array}{l}\text { Antifungal } \\
\text { efficacy }\end{array}$ \\
\hline \multicolumn{6}{|l|}{ Ex vivo models } \\
\hline $\begin{array}{l}\text { Corneocytes, } \\
\text { cornified layer } \\
\text { sheets, nail and hair } \\
\text { fragments }\end{array}$ & + & & & & \pm \\
\hline Skin explant & + & + & \pm & \pm & + \\
\hline \multicolumn{6}{|l|}{ In vitro models } \\
\hline $\begin{array}{l}\quad \text { Culture of } \\
\text { keratinocytes, PMN, } \\
\text { or macrophages }\end{array}$ & & & & + & \\
\hline $\begin{array}{l}\text { Skin equivalents } \\
\text { reconstructed in } \\
\text { culture }\end{array}$ & + & + & & + & + \\
\hline \multicolumn{6}{|l|}{ In vivo models } \\
\hline Animal models & + & + & + & & + \\
\hline
\end{tabular}

using skin explants can be used to study the local responses given by either keratinocytes or cells of the innate immunity located in the epidermis and dermis of the explant.

Finally, testing efficacy of antifungal compounds is performed using ex vivo model of skin explant, in vitro model of skin equivalent, or in vivo animal model. Indeed, these three models cover the analysis of complete infection processes by dermatophytes and allow to evaluate the efficacy of antifungal compounds, whatever their mode of action. To a lesser extent, ex vivo models using corneocytes in suspension, cornified layer sheets, or nail and hair fragments, can be used to monitor the efficacy of compounds targeting the adhesion processes deployed by dermatophytes.

\section{Experimental Models to Study Infectious Processes During Dermatophytosis}

Dermatophytes infect host tissues through three successive steps: adhesion, germination, and invasion (Fig. 2a). In reaction to tissue invasion by dermatophytes, host cells become activated, most likely in order to initiate antifungal defenses and counteract the infection. Mechanisms involved during the infectious process as well as cellular responses triggered in host tissue can be both investigated by mean of experimental models of dermatophytosis, as mentioned above and depicted in details hereunder. 

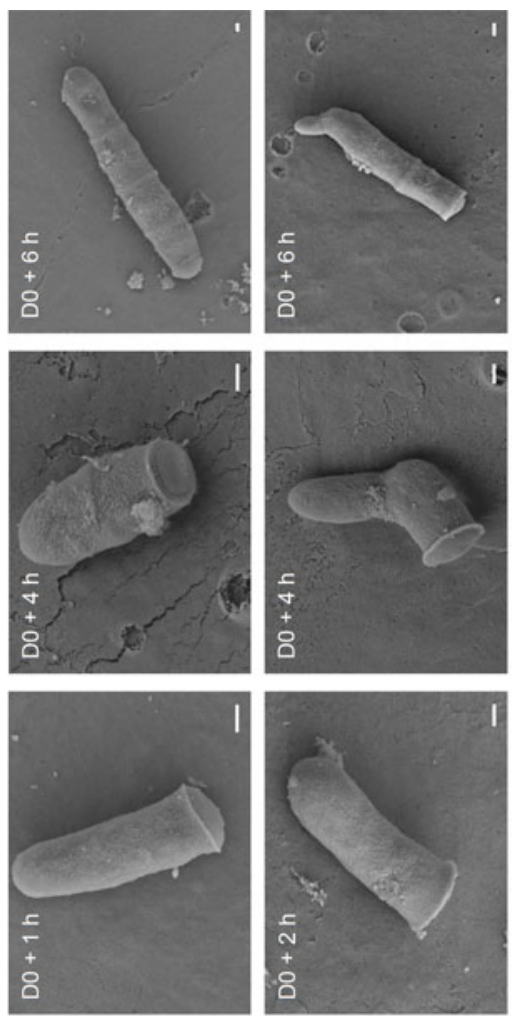

$\infty$

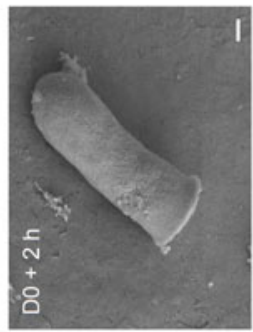

뭉
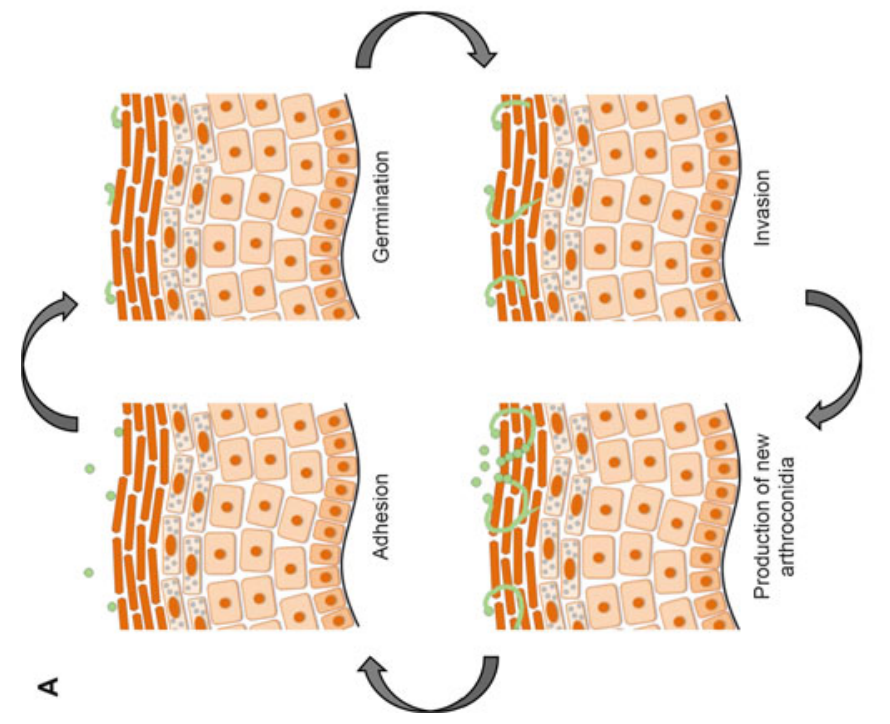

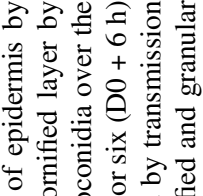

ธี 记吉专完

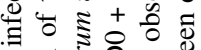

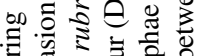
吾芯言起 오을 跣

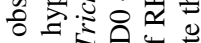
क की

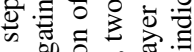

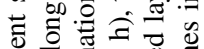

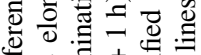

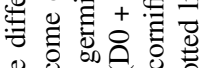
5 o ปี 누의

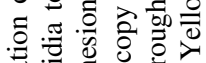
氙 氞 ४

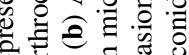
ญ

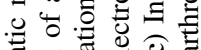
유워

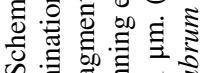
ผ 可馬 (동

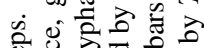

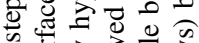

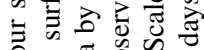
○。 . ธี

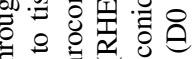
플

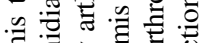

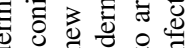
을

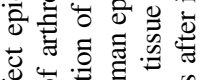

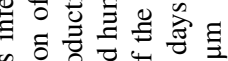

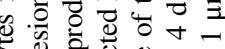

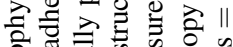
各踏

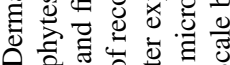
응 \& 0 등

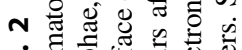

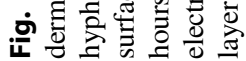




\subsection{Adhesion to the Host Tissue}

Adhesion is the first step of tissue infection by dermatophytes and involves close contact between arthroconidia and the surface of the host epidermis. Notably, analysis by electron microscopy have revealed that arthroconidia or microconidia from $T$. mentagrophytes and T. interdigitale, inoculated on human skin explants, produce fibrils that connect them to the epidermal surface [30, 38, 39].

\subsubsection{Adhesion Is an Early Process in the Infection Development}

Several studies performed on different experimental models of dermatophytosis have characterized the adhesion kinetics of dermatophytes to the host tissue. By light microscopy, Zurita and Hay [19] observed arthroconidia from three different Trichophyton species (i.e., T. rubrum, T. interdigitale, and T. quinckeanum) adhering to corneocytes in suspension. Their observations revealed that adhesion occurs as soon as after $2 \mathrm{~h}$ of contact, reaching a maximum after $4 \mathrm{~h}$. Moreover, those authors report increased adhesion of $T$. interdigitale and $T$. rubrum to corneocytes from plantar skin, whereas the adhesion to corneocytes isolated from forearm skin is weaker, suggesting that the strength of dermatophyte adhesion varies upon body location. Accordingly, arthroconidia from T. interdigitale or T. mentagrophytes adhere to cornified layer sheets as soon as $1 \mathrm{~h}$ after tissue exposure and their adhesion increasingly occurred during the first $6 \mathrm{~h}$ of contact [30]. Other studies using microscopy further showed that adhesion of $T$. mentagrophytes on ex vivo models based on human nail fragments [60] or on human skin explants [38] started, respectively, 6 or $12 \mathrm{~h}$ after infection. Finally, adhesion of $M$. canis arthroconidia to the surface of RFE can be observed under a fluorescent light microscope after labeling arthroconidia with Calcofluor White. In this case, adhesion was shown starting within $2 \mathrm{~h}$ and increased up to $6 \mathrm{~h}$ after infection [61].

More recently, adhesion assays based on colony-forming units (CFU) counting have been developed. In one method, arthroconidia adhering to skin explants from human or other animal species were recovered by scrapping and were seeded over Sabouraud agar for a few days at $27^{\circ} \mathrm{C}$ in order to assess the number of CFU which were adherent $[35,36]$. This kind of assay demonstrated strong adhesion of $M$. canis arthroconidia over skin explants after $4 \mathrm{~h}$ of exposure. On the other hand, a second method developed using an in vitro model of dermatophytosis on RHE, rather assessed the number of non-adherent arthroconidia in a defined number laid over the epidermal tissue [27]. Practically, non-adherent arthroconidia were recovered by several washes of the tissue surface before being seeded over Sabouraud agar and counting of $\mathrm{CFU}$ as above. Knowing the initial number of arthroconidia entering in contact with the RHE, the number of adherent arthroconidia was determined by simple calculation. By using this method, it was shown that arthroconidia of T. rubrum start to adhere to RHE as soon as $1 \mathrm{~h}$ after infection and that $T$. rubrum adhesion increases for the first $24 \mathrm{~h}$ of exposure.

Altogether, these data suggest that adhesion is an early process in infection development and that it increases over time. 


\subsubsection{Surface Molecules and Secreted Proteases Are Required for Adhesion}

Currently, the precise mechanisms used by dermatophytes to adhere to the host tissues are still incompletely understood. However, pieces of information have been obtained by the mean of experimental models of dermatophytosis. Interestingly, adhesion seems to rely on complex processes that simultaneously involve molecules expressed at the surface of arthroconidia and secreted proteases (reviewed by Baldo et al. [62]).

In such context, the study of interactions between $T$. mentagrophytes or T. rubrum with mutant Chinese ovary epithelial cells expressing various terminal carbohydrates on their cell surface revealed that mannose and galactose-binding proteins are present on the surface of microconidia [63, 64]. Accordingly, Bitencourt et al. [65] observed that T. rubrum aleurioconidia express a gene encoding an adhesin-like protein when they are cocultured with human keratinocytes. As other fungal adhesins [66-68], this adhesin-like protein contains a central domain with a tandem repeat sequence whose length and number of repeats likely influence adhesion ability of the different dermatophyte species or strains.

In addition, dermatophytes express a huge number of proteases, including subtilisin proteases (Sub), metalloproteases (Mep), and leucine aminopeptidases (Lap), which seem all implied in adhesion and invasion processes [62, 69]. Since the proteases Sub1, Sub3, Sub4, Lap1, Lap2, and Mep4 are highly expressed by dermatophytes when they are cultured in a protein-rich medium $[40,41,65,70$, 71], they were long ago considered as virulence factors. Recent studies though have shown that proteases expressed by dermatophytes differ during in vivo infection: for instance, Sub6 is the main protease expressed by $T$. benhamiae during experimental infection on Guinea pig [40, 41], and by T. rubrum inside onychomycosis lesions naturally induced in humans [72]. Besides, even if Sub3 is not the main protease expressed in vivo, Sub3 was detected by immunohistochemistry in the skin of Guinea pig experimentally infected with $M$. canis [73]. Such a difference between in vitro and in vivo studies underlines the importance of suitable experimental models.

Proteases of the subtilisin family, especially Sub3, have been shown to have a major role in dermatophyte adhesion. Indeed, adhesion of $M$. canis arthroconidia to RFE surface is reduced by the chymostatin inhibitor which targets serine-proteases including subtilisins, and by specific antibody against Sub3, although in a lesser extent [61]. In addition, the adhesion of a $M$. canis strain invalidated for Sub3 by RNA silencing [74] to cutaneous explants from humans or other animals is decreased by comparison with a control strain of $M$. canis expressing Sub3 [35, 36]. Using an experimental model of dermatophytosis on RHE [27], we confirmed the involvement of subtilisin proteases in the adhesion of T. rubrum to the epidermal surface (Fig. 3). First, the inhibiting activity of chymostatin on that of Sub3 was verified, either in the absence and in the presence of the RHE, thanks to an assay based on an artificial substrate for this protease ( $N$-succinyl-Ala-Ala-Pro-PheP-nitroanilide Sigma cat. no. S7388) (Fig. 3a). In addition, the viability of RHE was controlled when exposed to chymostatin (Fig. 3b). Infection of RHE was then 


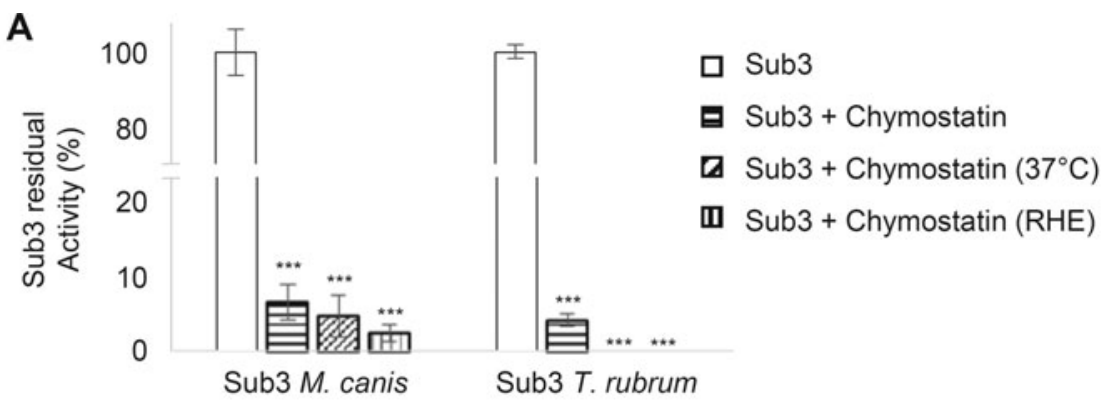

B
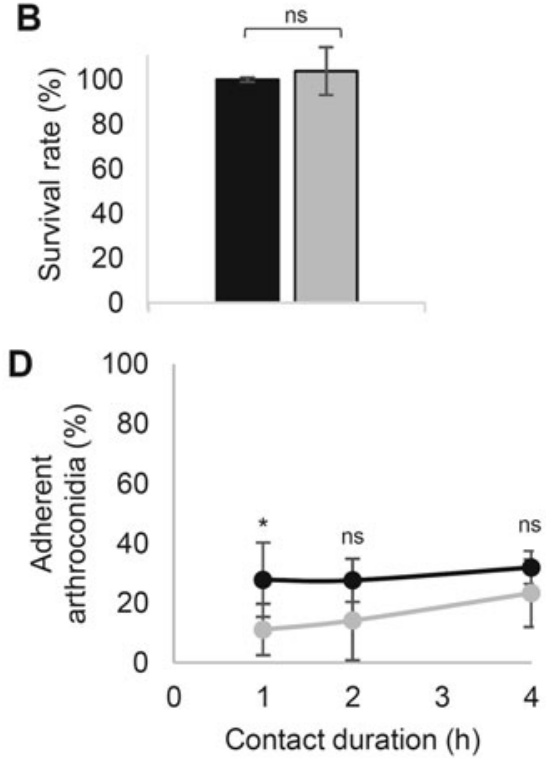

C

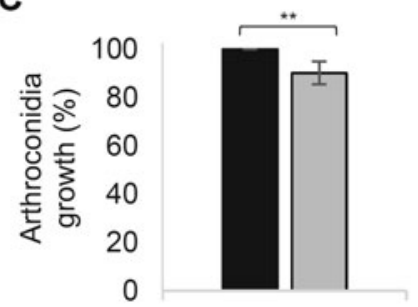

E

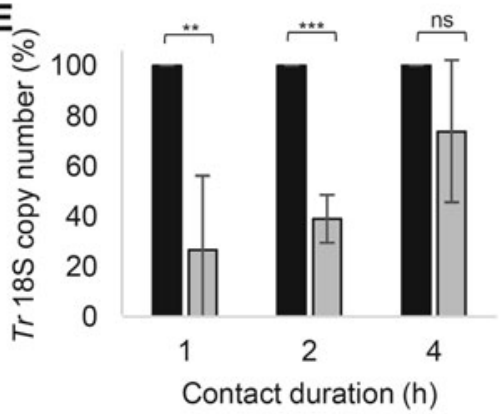

$\mathbf{F}$

Contact duration

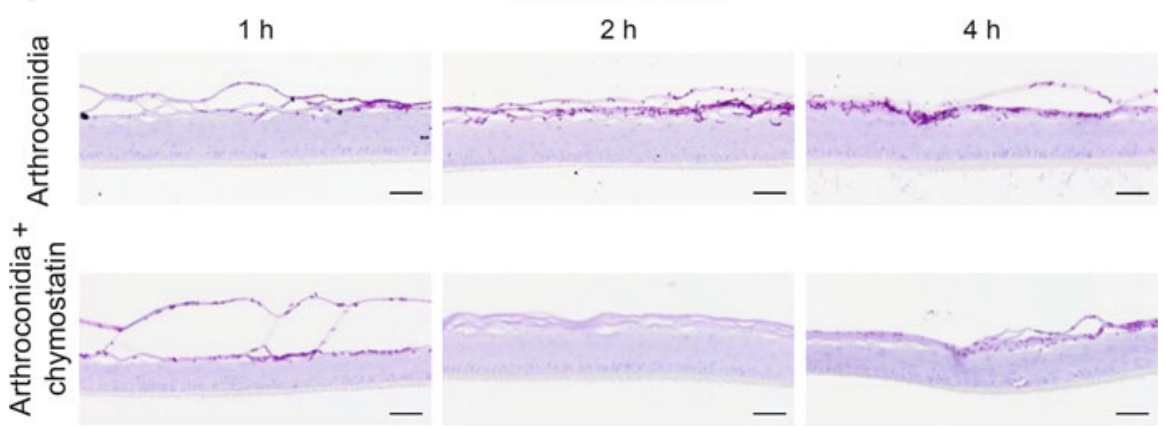

Fig. 3 Serine proteases are involved in the adhesion process of arthroconidia to host epidermis. (a) Residual activity of recombinant subtilisin-3 (Sub3) serine proteases from Trichophyton rubrum or Microsporum canis alone (white), in the presence of $100 \mu \mathrm{M}$ chymostatin either under optimal conditions (horizontal hatchings), or after $4 \mathrm{~h}$ incubation at $37^{\circ} \mathrm{C}$ (diagonal hatchings) or after $4 \mathrm{~h}$ incubation in topical application on reconstructed human epidermis (RHE) at $37{ }^{\circ} \mathrm{C}$ (vertical hatchings) ( $n=3 \pm \mathrm{SD} ;{ }^{* * *} p<0.001$ in comparison to the activity of Sub3 alone; ANOVA1). 
performed by topical exposure to T. rubrum arthroconidia, in the presence or not of chymostatin $(100 \mu \mathrm{M})$, followed by washes of their surface in order to eliminate non-adherent arthroconidia after 1, 2, or $4 \mathrm{~h}$ of infection. Non-adherent arthroconidia recovered by washing were numbered as described above after seeding on Sabouraud agar, taking into account the effect of chymostatin on the growth of arthroconidia (Fig. 3c), in order to calculate the percentage of adherent arthroconidia (Fig. 3d). Adhesion is slightly reduced by the presence of chymostatin, especially when contact duration was as short as $1 \mathrm{~h}$. This decrease in adhesion resulted, 4 days after infection, in a decrease in the number of fungi detected on the epidermal surface, as assessed by PCR quantification of the copy number of T. rubrum ribosomal DNA 18S (Fig. 3e) and by histological analysis after periodic acidSchiff (PAS)-staining of infected RHE (Fig. 3f). Therefore, proteases of the subtilisin family appear clearly involved in the adhesion of dermatophytes to the host tissue, even if mechanisms promoting adhesion are still unclear.

\subsection{Germination and Invasion of the Host Tissue}

After adherence to host tissue, arthroconidia initiate germination. Once arthroconidia adhere to the host tissue, they are able to perceive that this environment is favorable for their growth and they initiate the germination step during which they may swell before producing germ tubes that will elongate to become hyphae [75]. Germination is initiated when arthroconidia produce a germ tube with a length at least equivalent to the one of the initial arthroconidia. In ex vivo models based on corneocytes in suspension [19] or on sheets of cornified layer [31], the germination of arthroconidia, respectively, from $T$. interdigitale and $T$. mentagrophytes, was observed after $4 \mathrm{~h}$ of incubation. Simultaneously though, aleurioconidia of $T$. interdigitale adherent to suspended corneocytes do not exhibit germination yet [19]. In accordance with a delayed germination of aleurioconidia, T. mentagrophytes microconidia inoculated on human skin explant seemed to start germination after $24 \mathrm{~h} \mathrm{[38],} \mathrm{while} \mathrm{germina-}$ tion of T. rubrum conidia was observed later, 2 days after infection on human skin

Fig. 3 (continued) (b) Survival rate of RHE after $4 \mathrm{~h}$ incubation in the presence of chymostatin (gray) compared with control untreated RHE (black) ( $n=3 \pm \mathrm{SD}$; ${ }^{\mathrm{ns}} p \geq 0.05 ; t$ Student). (c) Growth of arthroconidia on Sabouraud agar in untreated conditions (black) or in the presence of chymostatin (gray) ( $n=4 \pm \mathrm{SD} ;{ }^{* *} p<0.01 ; t$ Student). (d) Adhesion of arthroconidia to RHE in the presence (gray) or not (black) of chymostatin expressed as percent of the number of arthroconidia initially applied on the epidermal surface, depending on contact duration with RHE ( $n=3 \pm \mathrm{SD} ;{ }^{*} p<0.05,{ }^{\mathrm{ns}} p \geq 0.05 ; t$ Student). (e) Quantification of $18 \mathrm{~S}$ rDNA gene copy number of $T$. rubrum by qPCR after total DNA extraction from infected RHE performed 4 days after infection by arthroconidia in the presence (gray) or not (black) of chymostatin, depending on the duration of contact with $\operatorname{RHE}\left(n=3 \pm \mathrm{SD} ;{ }^{* *} p<0.01,{ }^{* * *} p<0.001,{ }^{\mathrm{ns}} p \geq 0.05 ; t\right.$ Student). (f) Periodic acid-Schiff (PAS) staining with $\alpha$-amylase pretreatment and hemalun counterstaining of histological sections prepared from RHE 4 days after their infection by T. rubrum arthroconidia, after 1,2 , or $4 \mathrm{~h}$ of exposure in the presence or not of chymostatin. Scale bars $=50 \mu \mathrm{m}$ 
equivalent [56]. By scanning electron microscopy performed on infected RHE (Fig. 2b), one can observe T. rubrum arthroconidia adhering to the tissue surface as early as after $1 \mathrm{~h}$ of contact. Later on, arthroconidia that become slightly swollen and germinate can be seen after $4 \mathrm{~h}$. Elongating septate hyphae formed from germinated arthroconidia are observed after $6 \mathrm{~h}$ and become able to penetrate the host tissue during the invasion step.

During invasion, hyphae progress through the host tissue while continuing to elongate. Initial microscopic observations suggested that dermatophytes invade the host tissue by progressing through intercellular spaces without causing extensive damages to the cells. Indeed, $72 \mathrm{~h}$ after infection, $T$. mentagrophytes arthroconidia were observed invading sheets of cornified layer [31] or nail fragments [60] by progressing into intercellular spaces. In accordance, 3 days after infection, hyphae from $T$. mentagrophytes were found penetrating human skin explants between cells of the cornified layer and separating them [38]. In the dermatophytosis model on RHE developed by our team [27], we also observed using transmission electron microscopy analysis of infected tissues that hyphae are present in intercellular spaces between corneocytes 4 days after exposure to T. rubrum arthroconidia (Fig. 2c). These results suggest that dermatophytes are able to degrade intercellular junctions (e.g., corneodesmosomes or tight junctions) and/or the extracellular lipid matrix. In addition, these observations also suggest that hyphal elongation is orientated according to the physical and topographical features of the substrate in order to facilitate its invasion, a phenomenon known as "thigmotropism" [76]. This ability of dermatophytes to orientate their growth was also described by Perera et al. [77] who observed the growth of Epidermophyton floccosum, M. canis, and T. mentagrophytes on artificial membranes.

In addition to the above-described properties, dermatophytes secrete several proteases that exhibit specificity toward hard keratin substrates [69], rendering these fungi able to invade host tissue directly through corneocytes. Accordingly, scanning electron microscopy revealed penetration of corneocytes by T. mentagrophytes hyphae, resulting in damage to the corneocyte surface $21 \mathrm{~h}$ after the infection of cornified layer sheets [31]. Moreover, Jensen et al. [78] observed hyphae inside the corneocytes on human skin biopsy from Tinea corporis lesion. By infecting nail or hair fragments with various mutants of $T$. benhamiae, the critical role of the enzyme cysteine dioxygenase Cdo1 and of the sulfite efflux pump SSu1 in the degradation of keratinized structures by dermatophytes could be demonstrated [23]. Actually, thanks to Cdo1 and Ssu1, sulfite are produced by dermatophytes from environmental cysteine and secreted. As a reducing agent, sulfite can then cleave keratin-stabilizing cysteine bonds, rendering keratin more accessible for its degradation by proteases. Growth of strains deficient for one of the two (Cdo1 or Ssu1) proteins was indeed impaired on hair or nail fragments. Besides, Sub3, which seems involved in adhesion processes, is not required for invasion of the host tissue by dermatophytes. Indeed, arthroconidia from a M. canis strain invalidated for Sub3 produced hyphae able to invade the epidermis of experimentally infected Guinea pigs when the adhesion deficiency is artificially compensated by poloxamer 407, increasing the remanence of arthroconidia at the infection site [35]. 
It therefore appears that dermatophytes invade the host tissue by progressing simultaneously between and through corneocytes. Anyway, invasion of the cornified layer leads to alterations of the epidermal barrier, as observed on skin biopsy collected from Tinea corporis lesions [78]. Alterations of the epidermal barrier in response to dermatophyte infection of the in vitro RHE model were characterized by measurement of transepithelial electrical resistance, by assessing the outside-in permeability, together with the inside-out permeability [58]. While the two former assays confirmed loss of integrity in the epidermal barrier 4 days after the infection of RHE, the latter assay indicated that this loss can be partly due to the disorganization of tight junctions.

Finally, it is important to note that the infection by dermatophytes in vivo remains superficially localized in the keratinized structures (i.e., cornified layer of the epidermis, nails, and hairs), their progression into living tissues being probably blocked by the host immune system [7, 10]. However, in dermatophytosis models based on skin equivalent $[27,56]$ or on skin explant [38], the invasion reaches deeper epidermal layers in a few days, leading to the disorganization of the host tissue. This can be explained by the total absence of immune cells in skin equivalents, whereas cells from the innate immunity are sometimes present in skin explants, even if adaptive immunity is nonetheless missing. Those observations highlight the importance to monitor the development of infection in experimental models in order to perform assays and measurements when invasion is similar to that observed in vivo during natural infection.

\subsection{Host Responses Against Dermatophytosis}

Host responses against infecting dermatophytes include both activation of local cells and recruitment and activation of immune cells. Additionally, some dermatophytes also deploy several mechanisms to evade or silence host immune response.

\subsubsection{Recruitment of the Immune System Through Activation of Local Cells}

Experimental animal models are necessary to study the entire recruitment and activation of the host immune system in response to dermatophytosis. Firstly, Green et al. [79] demonstrated the requirement of cell-mediated immunity to fight against dermatophytosis by observing that nude mice experimentally infected by T. mentagrophytes were unable to heal. In accordance, Calderon and Hay [80] showed that transfer of $\mathrm{T}$ cells from mice acutely infected by T. quinckeanum into naive mice resulted in their protection against infection by this fungus. Conversely, serum transfer did not confer any protection. Later, secretion of interferon-gamma (IFN $\gamma$ ) and recruitment of macrophages were detected in the skin of wild-type mice experimentally infected by T. rubrum, whereas IFN $\gamma$ or interleukin (IL)-12 knockout mice presented higher fungal burdens and lower macrophage recruitment than wildtype animals [45]. Those observations suggested that the Th1 immune response, 
implying IFN- $\gamma$ production and macrophages activation, was the effective response allowing to control and resolve infection by dermatophytes [81, 82].

However, emerging data tend to show that the Th17 immune response could also be required for the control of dermatophyte infection [25, 29]. Indeed, using mouse models based on T. quinckeanum [83], T. mentagrophytes [84], or T. benhamiae [42], it was shown that PMN were recruited in large numbers to the infection site. Secretion of cytokines involved in the Th17 response (i.e., IL-6, IL-17A, IL-23, and transforming growth factor (TGF)- $\beta$ ) was also reported during experimental infection by $T$. mentagrophytes and $T$. benhamiae on mouse models [42, 84]. The involvement of the Th17 immune response in dermatophytosis clearance was finally clearly demonstrated in a recent study comparing $M$. canis infection on wild-type or IL-17RA or IL-17A/F-deficient mice: while it remains superficially localized in the cornified layer of wild-type mice, $M$. canis extensively colonizes the epidermis when the Th17 pathway is dysfunctional [25].

Interestingly, the recent report by Heinen et al. [29] reconciled all data since they observed that $\mathrm{T}$ cells isolated from the skin-draining lymph nodes of mice experimentally infected by $T$. benhamiae exhibit both Th1 and Th17 differentiation as assessed through cytokines production (IL-17A, IL-22, IFN $\gamma$ ) and transcription factors mRNA expression (retinoic acid receptor-related orphan receptor $\gamma \mathrm{t}$ and T-box transcription factor). In addition, they showed that fungal clearance and clinical recovery are lower in IFN $\gamma$ and IL-17A double-deficient mice than in IFN $\gamma$ or IL-17A single-deficient mice, suggesting complementary roles of Th1 and Th17 immune responses.

On another hand, some studies performed on simpler models, such as cells cultured either in suspension or in monolayers, as well as skin equivalents reconstructed in culture, allowed to monitor the specific activation of various cell types in response to dermatophytosis. Keratinocytes are the first cells to encounter dermatophytes and to react to their presence by production of cytokines and AMP. Indeed, human keratinocytes cultured as monolayers, in the presence of different dermatophyte species, exhibit release of several pro-inflammatory cytokines such as IL-1 $\alpha$, IL-1 $\beta$, IL-8, and tumor necrosis factor alpha (TNF $\alpha)$, growth factors like granulocyte-macrophage colony-stimulating factor (GM-CSF), and AMP including $\beta$-defensins-2 and -3 and protein S100A7 [12, 13, 26, 32, 33]. Similarly, mRNA expression and release of pro-inflammatory cytokines and AMP by keratinocytes embedded in skin equivalents are observed in such models exposed to infection by dermatophytes [26, 58]. Responses triggered in keratinocytes appear dependent on the dermatophyte species selected for epidermal infection, the release of cytokines being generally higher in the presence of zoophilic species, such as T. benhamiae or T. mentagrophytes, than in the presence of anthropophilic dermatophytes, i.e., T. rubrum or Trichophyton tonsurans [12, 13]. This reflects the high or low inflammatory levels observed in cutaneous lesions induced in vivo by the different species of dermatophytes and pledges again for the right model selection when studying specific dermatophytosis. Besides, the mRNA expression of TLR-2, -4, and -6 by keratinocytes cultured as monolayers was modulated during stimulation by T. rubrum [85]. 
By analysis of PMN maintained in culture, the release of IL-1 $\beta$, IL-8, and TNF $\alpha$ and the production of neutrophil extracellular traps (NET) by this cell type were observed when PMN are incubated in the presence of $T$. benhamiae or $M$. canis $[26,86]$. Overexpression of TLR-2 and -4 mRNA was further characterized in PMN exposed to $M$. canis [87]. In addition, release of TNF $\alpha$ and IL-1 $\beta$ by macrophages challenged by $T$. rubrum was measured on a simple culture model [34, 88]. Finally, IL-6, IL-8, IL-12, and TNF $\alpha$ were produced by dendritic cells upon contact with T. benhamiae or $M$. canis ([86]; Tabart, unpublished data).

Considering all these data, the antifungal response by the host tissue during epidermal dermatophytosis has been summarized in Fig. 4. Initially, keratinocytes detect the presence of dermatophytes through the recognition of specific fungal motifs by TLR, mainly TLR-2, -4 , and -6 . Activated keratinocytes start producing various pro-inflammatory cytokines, including IL- $1 \alpha$, IL- $1 \beta, \mathrm{IL}-8$, and TNF $\alpha$, which become upon release responsible for the recruitment of PMN and macrophages. Simultaneously, dendritic cells also detect dermatophytes via TLR or dectin receptors and subsequently participate to inflammation by their own secretion of pro-inflammatory cytokines. Thereafter, dendritic cells mature to become antigenpresenting cells and migrate into the lymph nodes in order to induce the differentiation of Th1 and Th17 cells, respectively, through the production of IL-12 or IL-6. Activated T cells then migrate to the infection site and secrete specialized cytokines: IFN $\gamma$ by Th1 cells, IL-17 and IL-22 by Th17 cells. IFN $\gamma$ stimulates macrophages which then become able to produce pro-inflammatory cytokines and to phagocyte small fungal elements. In the same time, the production by keratinocytes of PAM, responsible for direct antimicrobial effects, and GM-CSF is induced by IL-17 and IL-22. Finally, PMN are activated by GM-CSF and participate to the clearance of dermatophytes by phagocytosis, production of NET, and secretion of pro-inflammatory cytokines.

\subsubsection{Modulation of Host Immune Response by Dermatophytes}

Certain dermatophytes might dispose of mechanisms to evade or silence the immune response, causing chronic and low inflammatory lesions. Particularly, the anthropophilic T. rubrum species exhibits inhibition of macrophage functions and an induced secretion of anti-inflammatory proteins by macrophages and keratinocytes. Indeed, exposure of cultured macrophages to T. rubrum resulted in down-modulation of the major histocompatibility complex class II, in reduction of expression of co-stimulatory molecules, and in a upregulated release of IL-10 [34]. Moreover, T. rubrum further induced expression and release by keratinocytes of the anti-inflammatory protein encoded by $\mathrm{TNF} \alpha$-stimulated gene 6 [58]. Altogether, properties of T. rubrum which favor its adaptation to human host may explain why this species induces lower inflammatory lesions than zoophilic or geophilic dermatophytes. 


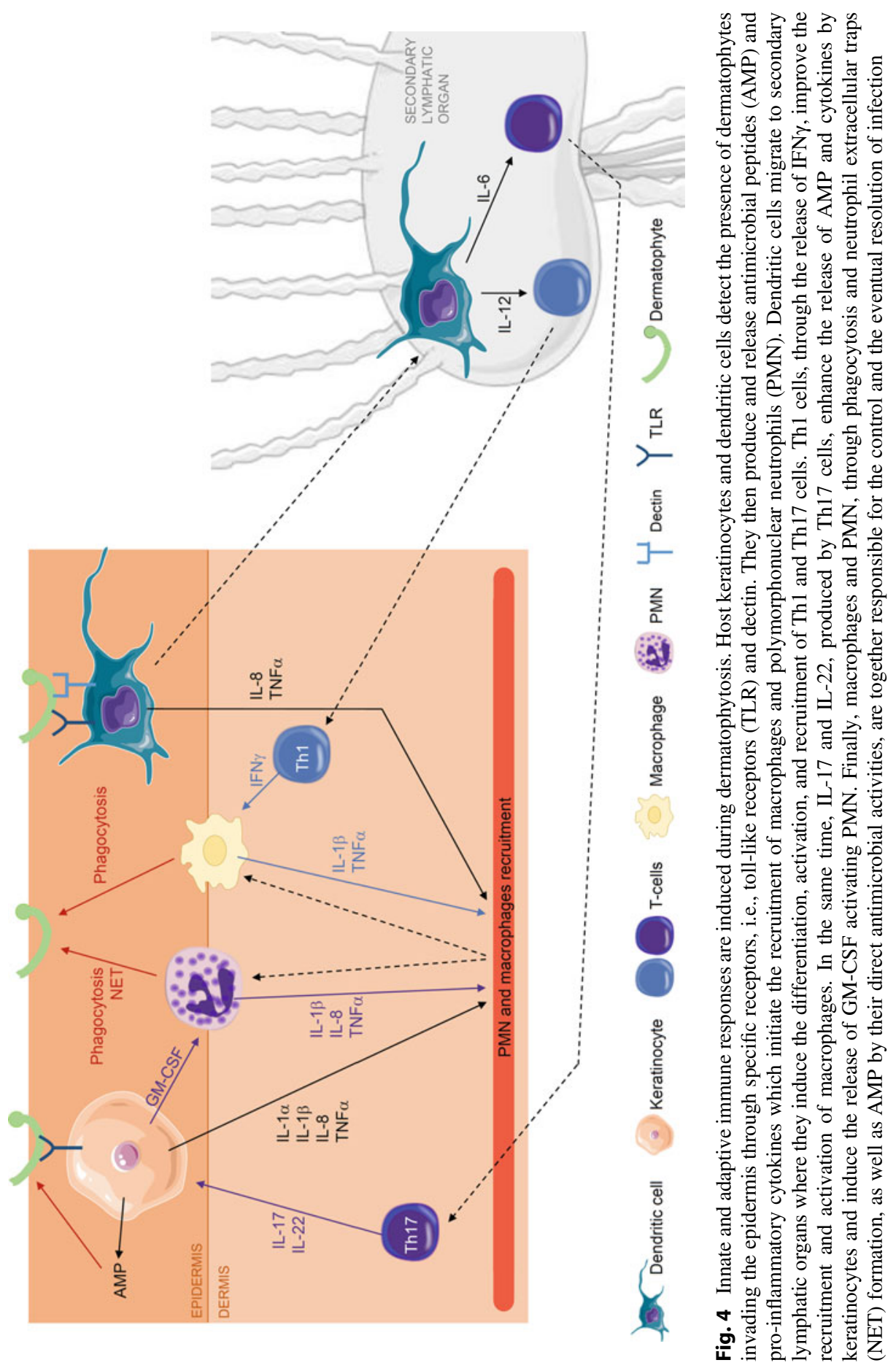




\section{$4 \quad$ Experimental Models to Evaluate Efficacy of Antifungal Compounds}

Although skin lesions produced during dermatophytosis may heal spontaneously within a few months, treatment is necessary in most cases. Several antifungal agents effective against dermatophytes are currently available. The most frequently used molecules are azole derivatives or terbinafine, both acting by inhibition of ergosterol synthesis, an essential compound for the organization of normal membrane in fungal cells [89]. Antifungal molecules are used for topical application or systemic administration, depending on the extension, severity, and accessibility of the lesion $[17,90]$. For instance, local administration is chosen to treat simple lesions of Tinea corporis or Tinea pedis, while systemic administration is often required for nail or hair lesions, as well as for severe or recalcitrant cutaneous lesions.

Despite the current availability of effective antifungal agents, the management of dermatophytosis must face several problems [17]. Firstly, the treatment of dermatophytosis may become long-lasting and thus expensive, leading too often to reduced compliance in patients who generally stop taking medication as soon as the clinical symptoms improve. Premature interruption of antifungal treatment contributes to the occurrence of an increasing number of cases of relapses and reinfections. Secondly, the systemic administration of some antifungal molecules is unfortunately accompanied by side effects on the central nervous system (e.g., headache, dizziness, concentration difficulties), on the gastrointestinal system (e.g., nausea, diarrhea, abdominal pain), and on the skin (e.g., erythema, rash, pruritus). In addition, toxicity for liver of systemic administration must be seriously considered [91]. Finally, treatments for dermatophytosis must cope with the emergence of drug resistance [92-94].

In view of problems linked to the existing treatments, but also because of an increasing incidence of dermatophytosis, the development of new antifungal compounds effective against dermatophytes becomes a real priority.

As explained above in this chapter, experimental models are essential to improve the current understanding of dermatophytosis pathogenesis, and are thus in good position to help in identifying new potential targets for antifungal strategies. In addition, experimental models allow an easy evaluation of the efficacy of antifungal compounds. Notably, animal models were considerably developed in the past for this purpose; for instance, terbinafine and itraconazole were both demonstrated efficient by the analysis of Guinea pigs experimentally infected by T. mentagrophytes or M. canis aleurioconidia [95, 96]. Since most antifungal agents are developed for human treatment, mainly targeting $T$. rubrum species, animal models of T. rubrum infection were also developed based on mouse [44] or Guinea pigs $[46,48]$, despite the difficulties in infecting animal with an anthropophilic dermatophyte (see Sect. 2.2).

Because the use of animal models is increasingly challenged, limited and even banned for ethical and political reasons, alternative methods are now considered. Thereby, ex vivo models of dermatophytes adhering to cornified layer sheet [97] or to corneocytes in suspension [19] were used to monitor the impact of photodynamic 
therapy or of antifungal molecules (i.e., ketoconazole, itraconazole, and griseofulvin) on adherence between dermatophytes and host cells. Furthermore, skin equivalent models were proved to provide valid methods to evaluate antifungal efficacy by using reference antifungal compounds such as terbinafine [55] or miconazole [27, 59]. Using a model of dermatophytosis on RHE, our group lately identified PD169316, a well-known specific inhibitor of the human p38 mitogen-activated protein kinase, as a potential antifungal agent effective against dermatophytes [58]. Indeed, PD169316 exhibits some direct effect on growth of fungi and thereby interferes with the infection of RHE by T. rubrum arthroconidia. Finally, a model of infection based on silkworm was recently developed by injection of T. mentagrophytes aleurioconidia in this invertebrate, in order to evaluate antifungal agents against dermatophytosis [98].

Therefore, each model appears as useful experimental device to identify and evaluate the efficacy of new antifungal molecules while, except for sheets of cornified layer, assessing potential toxicity for the treated tissue. In addition, one must keep in mind that arthroconidia are the infective elements produced in vivo by dermatophytes [21] and are more resistant than microconidia to some antifungal compounds [20]. In consequence, experimental models using arthroconidia as infective elements (e.g., $[27,55,59])$ must be considered as more appropriate to perform efficacy assay of antifungal molecules.

\section{Conclusion}

This chapter summarized experimental models for the investigations of both the infection process deployed by dermatophytes and the development of the host immune response. A better understanding of the pathogenesis of dermatophytosis will allow the identification of potential therapeutic targets and the subsequent development of new antifungal compounds. Since each type of model, whether ex vivo, in vitro, or animal model, holds characteristics bringing intrinsic advantages and limitations that make each of them more or less appropriate for precise investigations, the choice of one or another model must always consider the purpose of the study. For example, while simple in vitro models of keratinocytes cultured as monolayers remain useful to study particular responses of this host cell type exposed to dermatophytes, they are certainly less appropriate to investigate the recruitment of host immune cells and the activation of immunity. Conversely, animal models are suitable to evaluate the entire host immune responses, but do not allow in-depth focus on the activation of individual cells. In conclusion, a complete understanding of dermatophytosis will still depend upon the deployment of complementary experimental models. 


\section{References}

1. Seebacher C, Bouchara J, Mignon B. Updates on the epidemiology of dermatophyte infections. Mycopathologia. 2008;166:335-52.

2. Zhan P, Liu W. The changing face of dermatophytic infections worldwide. Mycopathologia. 2017;182:77-86.

3. Havlickova B, Czaika V, Friedrich M. Epidemiological trends in skin mycoses worldwide. Mycoses. 2008;51:2-15.

4. Hayette M, Sacheli R. Dermatophytosis, trends in epidemiology and diagnostic approach. Curr Fungal Infect Rep. 2015;9:164-79.

5. Saunte D, Holgersen J, Haedersdal M, Strauss G, Bitsch M, Svendsen O, et al. Prevalence of toe nail onychomycosis in diabetic patients. Acta Derm Venereol. 2006;86:425-8.

6. Eckhard M, Lengler A, Liersch J, Bretzel R, Mayser P. Fungal foot infections in patients with diabetes mellitus - results of two independent investigations. Mycoses. 2007;50:14-9.

7. Weitzman I, Summerbell R. The dermatophytes. Clin Microbiol Rev. 1995;8:240-59.

8. Lee W, Kim S, Jang Y, Lee S, Kim D, Bang Y, et al. Increasing prevalence of Trichophyton rubrum identified through an analysis of 115,846 cases over the last 37 years. J Korean Med Sci. 2015;30:639-43.

9. Degreef H. Clinical forms of dermatophytosis (ringworm infection). Mycopathologia. 2008;166:257-65.

10. Nenoff P, Krüger C, Ginter-Hanselmayer G, Schulte-Beerbühl R, Tietz H. Mycology - an update. Part 2: Dermatomycoses: clinical picture and diagnosis. J Dtsch Dermatol Ges. 2014;12:749-77.

11. Vermout S, Tabart J, Baldo A, Mathy A, Losson B, Mignon B. Pathogenesis of dermatophytosis. Mycopathologia. 2008;166:267-75.

12. Shiraki Y, Ishibashi Y, Hiruma M, Nishikawa A, Ikeda S. Cytokine secretion profiles of human keratinocytes during Trichophyton tonsurans and Arthroderma benhamiae infections. J Med Microbiol. 2006;55:1175-85.

13. Tani K, Adachi M, Nakamura Y, Kano R, Makimura K, Hasegawa A, et al. The effect of dermatophytes on cytokine production by human keratinocytes. Arch Dermatol Res. 2007;299:381-7.

14. Drake L, Scher R, Smith E, Faich G, Smith S, Hong J, et al. Effect of onychomycosis on quality of life. J Am Acad Dermatol. 1998;38:702-4.

15. Szepietowski J, Reich A. Stigmatisation in onychomycosis patients: a population-based study. Mycoses. 2009;52:343-9.

16. Nenoff P, Krüger C, Ginter-Hanselmayer G, Tietz H. Mycology - an update. Part 1: Dermatomycoses: causative agents, epidemiology and pathogenesis. J Dtsch Dermatol Ges. 2014;12:188-209.

17. Gupta A, Foley K, Versteeg S. New antifungal agents and new formulations against dermatophytes. Mycopathologia. 2017;182:127-41.

18. Deacon J. Fungal biology. 4th ed. London: Blackwell; 2006.

19. Zurita J, Hay R. Adherence of dermatophyte microconidia and arthroconidia to human keratinocytes in vitro. J Invest Dermatol. 1987;89:529-34.

20. Coelho L, Aquino-Ferreira R, Leite Maffei C, Martinez-Rossi N. In vitro antifungal drug susceptibilities of dermatophytes microconidia and arthroconidia. J Antimicrob Chemother. 2008;62:758-61.

21. Rashid A. Arthroconidia as vectors of dermatophytosis. Cutis. 2001;67:23.

22. Tabart J, Baldo A, Vermout S, Nusgens B, Lapiere C, Losson B, et al. Reconstructed interfollicular feline epidermis as a model for Microsporum canis dermatophytosis. J Med Microbiol. 2007;56:971-5.

23. Grumbt M, Monod M, Yamada T, Hertweck C, Kunert J, Staib P. Keratin degradation by dermatophytes relies on dioxygenase and a sulfite efflux pump. J Invest Dermatol. 2013;133:1550-5. 
24. Teixeira de Aguiar Peres N, Gomes da Silva L, da Silva Santos R, Jacob T, Persinoti G, Rocha L, et al. In vitro and ex vivo infection models help assess the molecular aspects of the interaction of Trichophyton rubrum with the host milieu. Med Mycol. 2016;54:420-7.

25. Burstein V, Guasconi L, Beccacece I, Theumer M, Mena C, Prinz I, et al. IL-17-mediated immunity controls skin infection and T Helper 1 response during experimental Microsporum canis dermatophytosis. J Invest Dermatol. 2018;138:1744-53.

26. Achterman R, Moyes D, Thavaraj S, Smith A, Blair K, Withe T, et al. Dermatophytes activate skin keratinocytes via mitogen-activated protein kinase signaling and induce immune responses. Infect Immun. 2015;83:1705-14.

27. Faway E, Cambier L, Mignon B, Poumay Y, Lambert de Rouvroit C. Modeling dermatophytosis in reconstructed human epidermis: a new tool to study infection mechanisms and to test antifungal agents. Med Mycol. 2017;55:485-94.

28. Cambier L, Mathy A, Baldo A, Bagut E, Tabart J, Antoine N, et al. Feline polymorphonuclear neutrophils produce pro-inflammatory cytokines following exposure to Microsporum canis. Vet Microbiol. 2013;162:800-5.

29. Heinen M, Cambier L, Antoine N, Gabriel A, Gillet L, Bureau F, et al. Th1 and Th17 immune responses act complementarily to optimally control superficial dermatophytosis. J Invest Dermatol. 2019;139:626-37.

30. Aljabre S, Richardson M, Scott E, Rashid A, Shankland G. Adherence of arthroconidia and germlings of anthropophilic and zoophilic varieties of Trichophyton mentagrophytes to human corneocytes as an early event in the pathogenesis of dermatophytosis. Clin Exp Dermatol. 1993;18:231-5.

31. Aljabre S, Richardson M, Scott E, Shankland G. Germination of Trichophyton mentagrophytes on human stratum corneum in vitro. J Med Vet Mycol. 1992;30:145-52.

32. Nakamura Y, Kano R, Hasegawa A, Watanabe S. Interleukin-8 and tumor necrosis factor alpha production in human epidermal keratinocytes induced by Trichophyton mentagrophytes. Clin Diag Lab Immunol. 2002;9:935-7.

33. Firat Y, Simanski M, Rademacher F, Schröder L, Brasch J, Harder J. Infection of keratinocytes with Trichophytum rubrum induces epidermal growth factor-dependent RNase 7 and human beta-defensin-3 expression. PLoS One. 2014;9:e93941.

34. Campos M, Russo M, Gomes E, Almeida S. Stimulation, inhibition and death of macrophages infected with Trichophyton rubrum. Microbes Infect. 2006;8:372-9.

35. Baldo A, Mathy A, Tabart J, Camponova P, Vermout S, Massart L, et al. Secreted subtilisin Sub3 from Microsporum canis is required for adherence to but not for invasion of the epidermis. Br J Dermatol. 2010;162:990-7.

36. Bagut E, Baldo A, Mathy A, Cambier L, Antoire N, Cozma V, et al. Subtilisin Sub3 is involved in adherence of Microsporum canis to human an animal epidermis. Vet Microbiol. 2012;160:413-9.

37. Baldo A, Chevigné A, Dumez M, Mathy A, Power P, Tabart J, et al. Inhibition of the keratinolytic subtilisin protease Sub3 from Microsporum canis by its propeptide (proSub3) and evaluation of the capacity of proSub3 to inhibit fungal adherence to feline epidermis. Vet Microbiol. 2012;159:479-84.

38. Duek L, Kaufman G, Ulman Y, Berdicevsky I. The pathogenesis of dermatophyte infections in human skin sections. J Infect. 2004;48:175-80.

39. Kaufman G, Horwitz B, Duek L, Ullman Y, Berdicevsky I. Infection stages of the dermatophyte pathogen Trichophyton: microscopic characterization and proteolytic enzymes. Med Mycol. 2007;45:149-55.

40. Staib P, Zaugg C, Mignon B, Weber J, Grumbt M, Pradervand S, et al. Differential gene expression in the pathogenic dermatophyte Arthroderma benhamiae in vitro versus during infection. Microbiology. 2010;156:884-95.

41. Tran T, De Col N, Feuermann M, Schmid-Slegert E, Bagut E, Mignon B, et al. RNA sequencing-based genome reannotation of the dermatophyte Arthroderma benhamiae and 
characterization of its secretome and whole gene expression profile during infection. mSystems. 2016;1:e00036-16.

42. Cambier L, Weatherspoon A, Defaweux V, Bagut E, Heinen M, Antoine N, et al. Assessment of the cutaneous response during Arthroderma benhamiae and A. vanbreuseghemii infection using an experimental mouse model. Br J Dermatol. 2014;170:625-33.

43. Cambier L, Heinen M, Mignon B. Relevant animal models in dermatophyte research. Mycopathologia. 2017;182:229-40.

44. Baltazar L, Werneck S, Carneiro H, Gouveia L, de Paula T, Byrro R, et al. Photodynamic therapy efficiently controls dermatophytosis caused by Trichophyton rubrum in a murine model. Br J Dermatol. 2015;172:801-4.

45. Baltazar L, Santos P, de Paula T, Rashid M, Cisalpino P, Souza D, et al. IFN- $\gamma$ impairs Trichophyton rubrum proliferation in a murine model of dermatophytosis through the production of IL-1 $\beta$ and reactive oxygen species. Med Mycol. 2014;52:293-302.

46. Li Z, Guo X, Dawuti G, Aibai S. Antifungal activity of ellagic acid in vitro and in vivo. Phytother Res. 2015;29:1019.

47. Chen X, Shen Y, Lü G, Liu W. Establishing an experimental Guinea pig model of dermatophytosis using Trichophyton rubrum. Acta Acad Med Sin. 2008;30:599-602.

48. Mei Y, Dai X, Yang W, Xu X, Liang Y. Antifungal activity of chitooligosaccharides against the dermatophyte Trichophyton rubrum. Int J Biol Macromol. 2015;77:330-5.

49. Kumar N, Goindi S. Statistically designed nonionic surfactant vesicles for dermal delivery of itraconazole: characterization and in vivo evaluation using a standardized Tinea pedis infection model. Int J Pharm. 2014;472:224-40.

50. Kumar N, Goindi S. D-optimal experimental approach for designing topical microemulsion of itraconazole: characterization and evaluation of antifungal efficacy against a standardized Tinea pedis infection model in Wistar rats. Eur J Pharm Sci. 2015;67:97-112.

51. Poumay Y, Dupont F, Marcoux S, Leclercq-Smekens M, Hérin M, Coquette A. A simple reconstructed human epidermis: preparation of the culture model and utilization in in vitro studies. Arch Dermatol Res. 2004;296:203-11.

52. Green C, Cheng G, Chandra J, Mukherjee P, Ghannoum M, Hoyer L. RT-PCR detection of Candida albicans $A L S$ gene expression in the reconstituted human epithelium (RHE) model of oral candidiasis and in model biofilms. Microbiology. 2004;150:267-75.

53. Bäsler K, Galliano M, Bergmann S, Rohde H, Wladykowski E, Vidal-y-Sy S, et al. Biphasic influence of Staphylococcus aureus on human epidermal tight junctions. Ann N Y Acad Sci. 2017;1405:53-70.

54. Jannasch M, Groeber F, Brattig N, Unger C, Walles H, Hansmann J. Development and application of three-dimensional skin equivalents for the investigation of percutaneous worm invasion. Exp Parasitol. 2015;150:22-30.

55. Rashid A, Edward M, Richardson M. Activity of terbinafine on Trichophyton mentagrophytes in human living skin equivalent model. J Med Vet Mycol. 1995;33:229-33.

56. Liang P, Huang X, Yi J, Chen Z, Ma H, Ye C, et al. A Trichophyton rubrum infection model based on the reconstructed human epidermis - Episkin ${ }^{\circledR}$. Chin Med J (Engl). 2016;129:54-8.

57. Faway E, Lambert de Rouvroit C, Poumay Y. In vitro models of dermatophyte infection to investigate epidermal barrier alterations. Exp J Dermatol. 2018;27:915-22.

58. Faway E, Cambier L, De Vuyst E, Evrard C, Thiry M, Lambert de Rouvroit C, et al. Responses of reconstructed human epidermis to Trichophyton rubrum infection and impairment of infection by the inhibitor PD169316. J Invest Dermatol. 2019;139(10):2080-2089.e6.

59. Tabart J, Baldo A, Vermout S, Losson B, Mignon B. Reconstructed interfollicular feline epidermis as a model for the screening of antifungal drugs against Microsporum canis. Vet Dermatol. 2008;19:130-3.

60. Rashid A, Scott E, Richardson M. Early events in the invasion of the human nail plate by Trichophyton mentagrophytes. Br J Dermatol. 1995;133:932-40. 
61. Baldo A, Tabart J, Vermout S, Mathy A, Collard A, Losson B, et al. Secreted subtilisins of Microsporum canis are involved in adherence of arthroconidia to feline corneocytes. J Med Microbiol. 2008;57:1152-6.

62. Baldo A, Monod M, Mathy A, Cambier L, Bagut E, Defaweux V, et al. Mechanisms of skin adherence and invasion by dermatophytes. Mycoses. 2011;55:218-23.

63. Esquenazi D, de Souza W, Sales Alviano C, Rozental S. The role of surface carbohydrates on the interaction of microconidia of Trichophyton mentagrophytes with epithelial cells. Immunol Med Microbiol. 2003;35:113-23.

64. Esquenazi D, Sales Alviano C, de Souza W, Rozental S. The influence of surface carbohydrates during in vitro infection of mammalian cells by the dermatophyte Trichophyton rubrum. Res Microbiol. 2004;155:144-53.

65. Bitencourt T, Macedo C, Franco M, Assis A, Komoto T, Stehling E, et al. Transcription profile of Trichophyton rubrum conidia grown on keratin reveals the induction of an adhesin-like protein gene with a tandem repeat pattern. BMC Genomics. 2016;17:249.

66. Verstrepen K, Klis F. Flocculation, adhesion and biofilm formation in yeasts. Mol Microbiol. 2006;60:5-15.

67. Brandhorst TT, Roy R, Wüthrich M, Nanjappa S, Filutowicz H, Galles K, et al. Structure and function of a fungal adhesin that binds heparin and mimics thrombospondin-1 by blocking $\mathrm{T}$ cell activation and effector function. PLoS Pathog. 2013;9:e1003464.

68. Hung CY, Yu JJ, Seshan KR, Reichard U, Cole GT. A parasitic phase-specific adhesin of Coccidioides immitis contributes to the virulence of this respiratory fungal pathogen. Infect Immun. 2002;70:3443-56.

69. Monod M. Secreted proteases from dermatophytes. Mycopathologia. 2008;166:285-94.

70. Mignon B, Swinnen M, Bouchara J, Hofinger M, Nikkels A, Pierard G, et al. Purification and characterization of a $31.5 \mathrm{kDa}$ keratinolytic subtilisin-like serine protease from Microsporum canis and evidence of its secretion in naturally infected cats. Med Mycol. 1998;36:395-404.

71. Leng W, Liu T, Wang J, Li R, Jin Q. Expression dynamics of secreted protease genes in Trichophyton rubrum induced by key host's proteinaceous components. Med Mycol. 2009;47:759-65.

72. Méhul B, Gu Z, Jomard A, Laffet G, Feuilhade M, Monod M. Sub6 (Tri r 2), an onychomycosis marker revealed by proteomics analysis of Trichophyton rubrum secreted proteins in patient nail samples. J Invest Dermatol. 2016;136:331-3.

73. Mignon B, Leclipteux T, Focant C, Nikkels A, Piérard G, Losson B. Humoral and cellular immune response to a crude exo-antigen and purified keratinase of Microsporum canis in experimentally infected Guinea pigs. Med Mycol. 1999;37:123-9.

74. Vermout S, Tabart J, Baldo A, Monod M, Losson B, Mignon B. RNA silencing in the dermatophyte Microsporum canis. FEMS Microbiol Lett. 2007;275:38-45.

75. Liu T, Zhang Q, Wang L, Yu L, Leng W, Yang J, et al. The use of global transcriptional analysis to reveal the biological and cellular events involved in distinct development phases of Trichophyton rubrum conidial germination. BMC Genomics. 2007;8:100.

76. Almeida M, Brand A. Thigmo responses: the fungal sense of touch. Microbiol Spectr. 2017;5 https://doi.org/10.1128/microbiolspec.FUNK-0040-2016.

77. Perera T, Gregory D, Marshall D, Gow N. Contact-sensing by hyphae of dermatophytic and saprophytic fungi. J Med Vet Mycol. 1997;35:289-93.

78. Jensen J, Pfeiffer S, Akaki T, Schröder J, Kleine M, Neumann C, et al. Barrier function, epidermal differentiation, and human $\beta$-defensin 2 expression in Tinea corporis. J Invest Dermatol. 2007;127:1720-7.

79. Green F, Lee KW, Balish E. Chronic T. mentagrophytes dermatophytosis of Guinea pig skin grafts on nude mice. J Invest Dermatol. 1982;79:125-9.

80. Calderon R, Hay R. Cell-mediated immunity in experimental murine dermatophytosis. II. Adoptive transfer of immunity to dermatophyte infection by lymphoid cells from donors with acute or chronic infections. Immunology. 1984;53:465-72.

81. Almeida S. Immunology of dermatophytosis. Mycopathologia. 2008;166:277-83. 
82. Mignon B, Tabart J, Baldo A, Mathy A, Losson B, Vermout S. Immunization and dermatophytes. Curr Opin Infect Dis. 2008;21:134-40.

83. Hay R, Calderon R, Mackenzie C. Experimental dermatophytosis in mice: correlation between light and electron microscopic changes in primary, secondary and chronic infections. Br J Exp Pathol. 1988;69:703-16.

84. Nakamura Y, Nishibu A, Yasoshima M, Tanoue C, Yoshida N, Hatta J, et al. Analysis of Trichophyton antigen-induced contact hypersensitivity in mouse. J Dermatol Sci. 2012;66:144-53.

85. Garcia-Madrid L, Huizar-Lopez M, Flores-Romo L, Islas-Rodriguez A. Trichophyton rubrum manipulates the innate immune functions of human keratinocytes. Cent Eur J Biol. 2011;6:902-10.

86. Heddergott C, Bruns S, Nietzsche S, Leonhardt I, Kurzai O, Kniemeyer O, et al. The Arthroderma benhamiae hydrophobin HypA mediates hydrophobicity and influences recognition by human immune effector cells. Eukaryot Cell. 2012;11:673-82.

87. Cambier L, Heinen M, Bagut E, Antoine N, Mignon B. Overexpression of TLR-2 and TLR-4 mRNA in feline polymorphonuclear neutrophils exposed to Microsporum canis. Vet Dermatol. 2016;27:78-e22.

88. Yoshikawa F, Ferreira L, de Almeida S. IL-1 signaling inhibits Trichophyton rubrum conidia development and modulates the IL-17 response in vivo. Virulence. 2015;6:449-57.

89. Ghannoum M, Rice L. Antifungal agents: mode of action, mechanisms of resistance, and correlation of these mechanisms with bacterial resistance. Clin Microbiol Rev. 1999;12:501-17.

90. Gupta A, Cooper E. Update in antifungal therapy of dermatophytosis. Mycopathologia. 2008;166:353-67.

91. Raschi E, Poluzzi E, Koci A, Caraceni P, De Ponti F. Assessing liver injury associated with antimycotics: concise literature review and clues from data mining of the FAERS database. World J Hepatol. 2014;6:601-12.

92. Osborne C, Leitner I, Favre B, Ryder N. Amino acid substitution in Trichophyton rubrum squalene epoxidase associated with resistance to terbinafine. Antimicrob Agents Chemother. 2005;49:2840-4.

93. Mukherjee P, Leidich S, Isham N, Leitner I, Ryder N, Ghannoum M. Clinical Trichophyton rubrum strain exhibiting primary resistance to terbinafine. Antimicrob Agents Chemother. 2003;47:82-6.

94. Salehi Z, Shams-Ghahfarokhi M, Razzaghi-Abyaneh M. Antifungal drug susceptibility profile of clinically important dermatophytes and determination of point mutations in terbinafineresistant isolates. Eur J Clin Microbiol Infect Dis. 2018;37:1841-6.

95. Ghannoum M, Hossain M, Long L, Mohamed S, Reyes G, Mukherjee P. Evaluation of antifungal efficacy in an optimized animal model of Trichophyton mentagrophytesdermatophytosis. J Chemother. 2004;16:139-44.

96. Saunte D, Hasselby J, Brillowska-Dabrowska A, Frimodt-Moller N, Svejgaard E, Linnemann D, et al. Experimental Guinea pig model of dermatophytosis: a simple and useful tool for the evaluation of new diagnostics and antifungals. Med Mycol. 2008;46:303-13.

97. Smijs T, Bouwstra J, Schuitmaker H, Talebi M, Pavel S. A novel ex vivo skin model to study the susceptibility of the dermatophyte Trichophyton rubrum to photodynamic treatment in different growth phases. J Antimicrob Chemother. 2007;59:433-40.

98. Ishii M, Matsumoto Y, Yamada T, Abe S, Sekimizu K. An invertebrate infection model for evaluating anti-fungal agents against dermatophytosis. Sci Rep. 2017;7:12289. 